\title{
An exploration of place: Towards an understanding of spatial character
}

\author{
$S D E K L E R K^{1}$
}

\begin{abstract}
Architecture and its influences on our daily life form the premise of the study. Every space has a character which is defined by the type of human engagement it solicits. Spaces have varying characters and the suitability of their use depends on whether they are experienced as enchanting or disenchanting. Hermeneutic phenomenology, which emphasise the importance of context when the experience of a phenomenon is considered, guides the investigation. Since the 1970's various architects have absorbed the hermeneutic phenomenology into their writings and work. Those referred to during the course of this paper include Christian Norberg-Schultz, Steven Holl, Peter Zumthor, Ziona Strelitz, Nabeel Hamdi and Juhani Pallasmaa.

Christian Norberg-Schultz translated hermeneutic phenomenology into architecture in his theory defining the Sense of Place. This theory delineates that there are two spatial qualities influencing the experience of an environment, namely, 'space' and 'character'. These qualities are interdependent and are therefore explored independently prior to their exploration as a singular whole.

An interdependent eco-system defining the relationship between the Context, User and Built Fabric is proposed within this paper. Observation and in-depth knowledge in all three areas is required for the creation of enchanted environments. If this system falls out of equilibrium, disenchanted environments develop. Enchanting environments engage their users and benefit the community and individuals alike. Disenchanted environments do not support their users, rendering their experience of architecture sombre and austere. The necessity of experiencing the world as a place, and not as a space, is a central theme throughout the paper.
\end{abstract}

Keywords: Hermeneutic phenomenology, understanding, architecture, place, spatiality, sense of place, context, user, built-fabric.

\section{Introduction ${ }^{2}$}

Architecture moulds spaces and thresholds to support activities, define movement and establish varying levels of intimacy and privacy for the user. The spaces we use daily have a significant impact on the way we experience life. These spatial experiences can either be enchanting or disenchanting, depending on the character of the environment. Various viewpoints will be layered in order to effectively illustrate the necessity and methodology for the creation of enchanted spaces. Several architectural theorists, social anthropologists, philosophers and researchers will be referred to in the development of the argument to ensure that there is an informed reflection on the phenomenon.

1. Sunica de Klerk is a guest researcher for the Department of Architecture, University of Pretoria. She is currently employed as an Interior Architect at Boogertman + Partners Architects, Pretoria. E-mail: sunica@boogertmanpta.co.za.

2. This paper was informed by the master's thesis: An exploration of office design: Understanding the character of our workplaces, by Sunica de Klerk and co-authors: Catherine Karusseit and Elana van der Wath, completed at the University of Pretoria in 2013. 
This paper aims to determine the qualities which define both enchanting and disenchanting environments. Furthermore, the possible solutions of translating the character of an environment from disenchanted to enchanted, will be investigated. Subsequently, a means towards the understanding and design of the character will be proposed.

A theoretical framework is developed which will be referenced as a benchmark for the investigation that follows (figure 1). The paper follows a hermeneutic phenomenological approach, which was originally developed by Heidegger and was later translated into architecture by Christian Norberg-Schultz. This approach offers an interpretive theoretical exploration of the character of spaces within their context, offering the reader an understanding of architectural concepts. The subject offers inter-disciplinary opportunities and so the aim is to investigate its validity in everyday life.

The importance of the character of 'place,' specifically the relationship between the spatial character and the user interface, and how these are influenced by the building's context, will be investigated. The discipline of architecture has the opportunity to greatly enhance or significantly constrain our daily movements, activities, gatherings and sensations. This paper will explore these parameters through cross-disciplinary theories and case studies that illustrate the distinctions between an enchanted and disenchanted world where the tangible and intangible qualities are equally important.

\section{Theoretical framework: The phenomenological perspective}

Phenomenological interpretations in architecture have expounded primarily since the 1970's when the two main approaches, as developed by classical phenomenologists, were absorbed into international architectural thinking. Hermeneutic phenomenology was chiefly developed by Edmund Husserl (1859-1938) and Maurice Merleau-Ponty (1908-1961). Husserl (2012) believed that an object needed to be bracketed before the experience relating to the object could be observed. This view was developed in his epoch theory and mainly revolved around the importance of the experience of the object in isolation. Architectural theory employs this branch of phenomenology within its research and design approaches (Merleau-Ponty, 1996) and is based on the removal of a phenomenon from its context for the purpose of considering its character.

In juxtaposition, Martin Heidegger (1889-1976) introduced the relevance of context within the realm of Hermeneutic phenomenology. This theory considers the interpretation, rather than the description of objects, as the most faithful representation of the true experience (Heidegger, 2008). Heidegger argues that the context of an object significantly contributes to the way the object is experienced. Heidegger believed that objects should not be isolated (bracketed) from their surroundings. He argued that we experience phenomenon in-theworld, and that the descriptive philosophy of hermeneutic phenomenology was inadequate for a homogeneous interpretation of the comprehensive experience. This secondary branch of classical phenomenology is generally absorbed within the linguistic, social and architectural realms and will henceforth guide this paper in its exploration of enchanted and disenchanted environments. The value of context in the experience of space is illustrated by various architects, theorists and researchers who absorbed the approach into their writings and work. This paper will refer to their reflections during the articulation of the investigation, namely, Christian Norberg-Schultz, Steven Holl, Peter Zumthor, Ziona Strelitz, Nabeel Hamdi and Juhani Pallasmaa. 
Descriptive

Phenomenology

Interpretive

Phenomenology
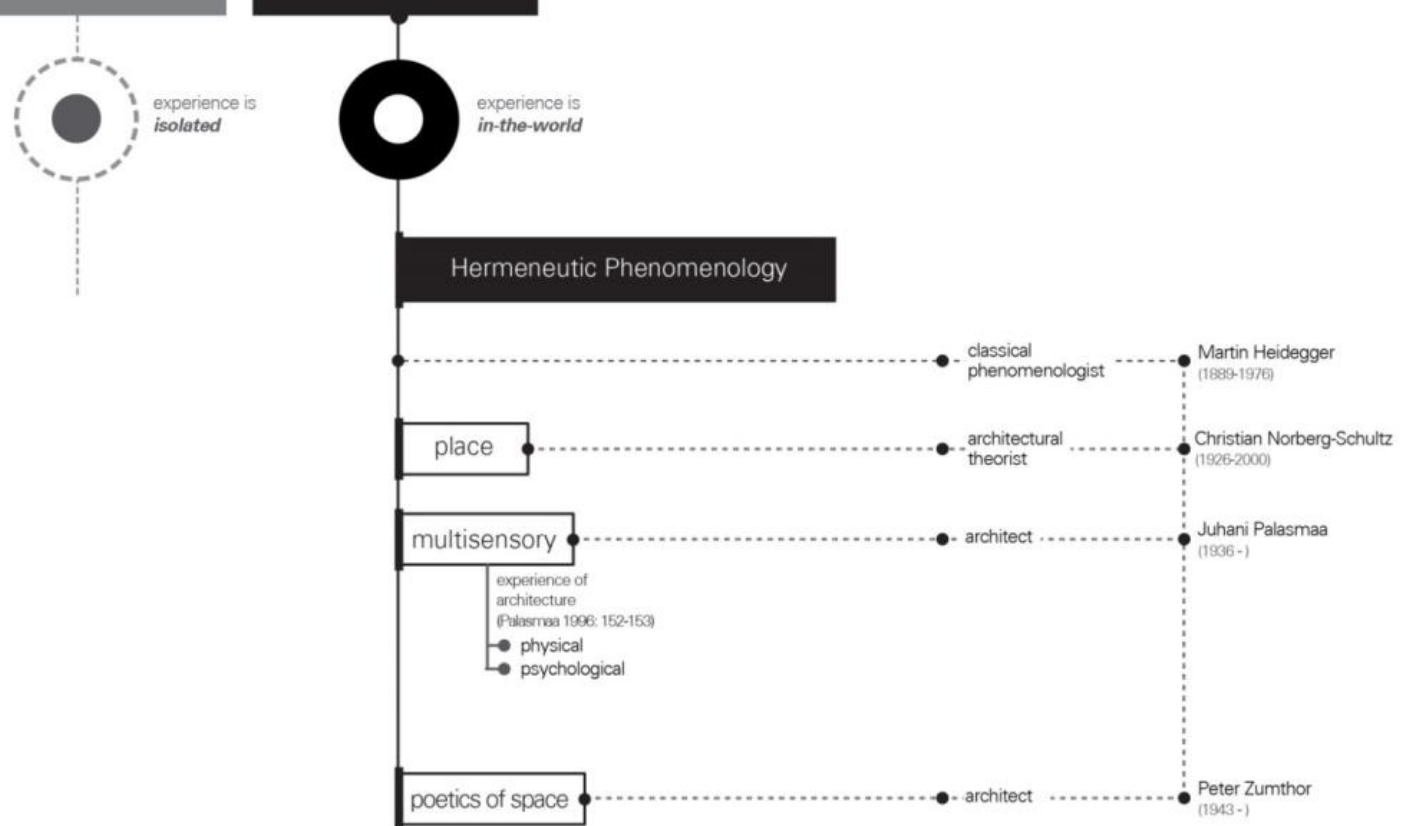

'Magic of the Real"

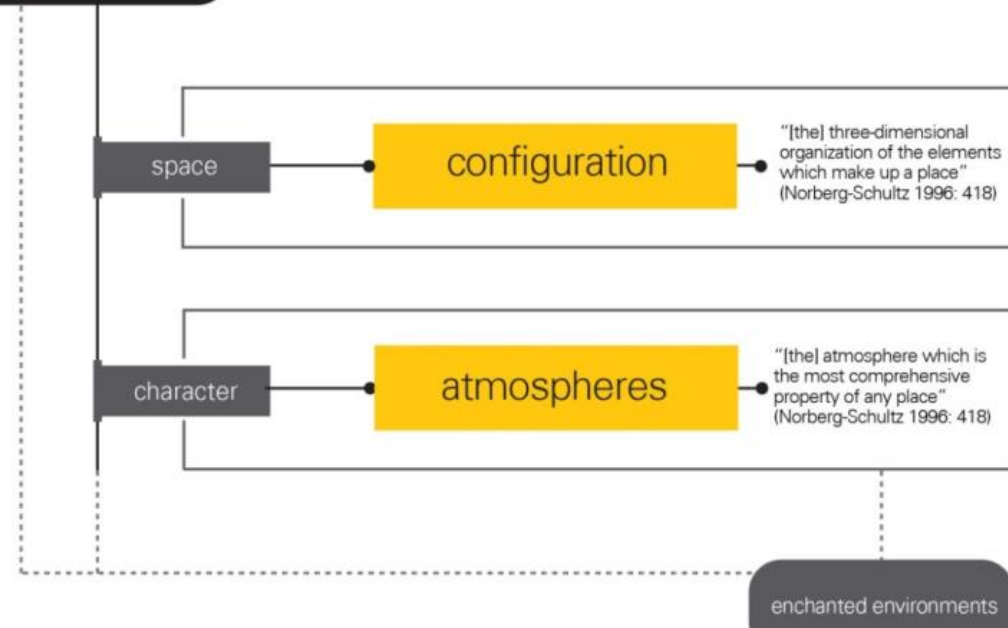

Figure 1. Diagrammatic exploration of the Theoretical Framework guiding the investigation (Author, 2015). 
Christian Norberg-Schultz, a Norwegian architectural theorist, translated hermeneutic phenomenology into architecture by establishing the profession as being more than merely the composition of space, but also as the arrangement's relationship to the surrounding context (Norberg-Schultz, 1996). This theory titled 'Sense of Place' (1996: 412) elaborates on Heidegger's writings on the relevancy of context. It stipulates that the spirit of a place is rooted in its context and that two defining categories can be denoted, namely 'space' and 'character'. Space is delineated as the "three-dimensional organisation of the elements which make up a place", while character is articulated as the "atmosphere which is the most comprehensive property of any place" (Norberg-Schultz, 1996: 418). He further emphasizes that since similar spatial configurations can have different characters, these qualities should be deemed interdependent. They should however be investigated separately prior to the exploration of their combined qualities in a singular whole. This concept is called "Lived Space" (Norberg-Schultz, 1996: 418) and specifically explores the spatial character by which spaces can be differentiated from places.

Peter Zumthor develops a vocabulary which investigates the factors that influence the experience of a place. Zumthor deems these factors as important architectural qualities as they determine how users interact with architecture's objects and spaces (Zumthor, 2006:17). Phenomenology is established as the best means for the analysis of the above-mentioned interaction between users and the Built Fabric by Juhani Pallasmaa (Pallasmaa, 1996: 450). Pallasmaa develops this argument by indicating that the multi-sensory experience of spaces impact upon us in both a physical and psychological manner. Pallasmaa makes a significant contribution to the understanding of the character of space by noting that, although the structure of feeling in a place may be diversified across cultures and individuals, the senses have the ability to awaken any human being's imagination and enrich our experience of an environment (Pallasmaa, 1996: 447-453). Peter Zumthor's vocabulary explores the way the built environment entices our senses, thereby activating our awareness of our environment and their impact on our experience within them.

When a user experiences an environment which is successfully connected to a multidimensioned context of social, physical and psychological spheres, the environment can be defined as being enchanted. Architecture is therefore required as mediator between spatial form and its experience. The theoretical investigation exploring the enigma mentioned above will now follow.

\section{Theoretical Investigations}

In this article the difference between an enchanted and a disenchanted environment is defined by the spatial experience of the user. Enchanted environments are comfortable, animated, inspiring and relate specifically to the requirements of the user, while disenchanted environments fail to provide the desired support users need, are uncomfortable and are unable to keep users interested in the activities at hand (Kemp \& Baker, 2006: xx).

The defining characteristics, 'space' and 'place,' which form the parameters constituting the formation of an enchanted environment, will now be explored. 


\section{Towards an understanding of "space"}

In terms of spatial configurations, an environment can be experienced as either a space or a place. The concepts of space and place are markedly different. A 'space' is in essence a nonplace. Non-places are explained by the French anthropologist Mark Augé as spaces which are, in their very nature, generic and offer no opportunity for individualisation (Augé 1995: 112). A place, in juxtaposition, is typically developed with a particular reference to specific users and their needs as well as the contextual fabric of the world around it. The characteristics of a space and place are directly linked to the structure of the experience of the user. This experience can either be enchanting or disenchanting. Therefore, architecture is not only a reflection of the thoughts and fashions of the time (the Zeitgeist), but also of the life and the dynamics of the use of the environment over time (Zumthor, 2010: 24). An environment's functionality, user interface, movement, scale, proportion, thresholds and response to context all influence the design's spatial configuration. The architect's apt interpretation of spatial requirements differentiates whether users experience it as a space or

Figure 2. Hong Kong Polytechnic University's “Innovation Tower” (Unknown, 2011). From: http://goo.gl/OXsWQ1.

Figure 3. Mori x Hako by UID Architects (Ueda, 2012). From: https://goo.g1/HKOsws.
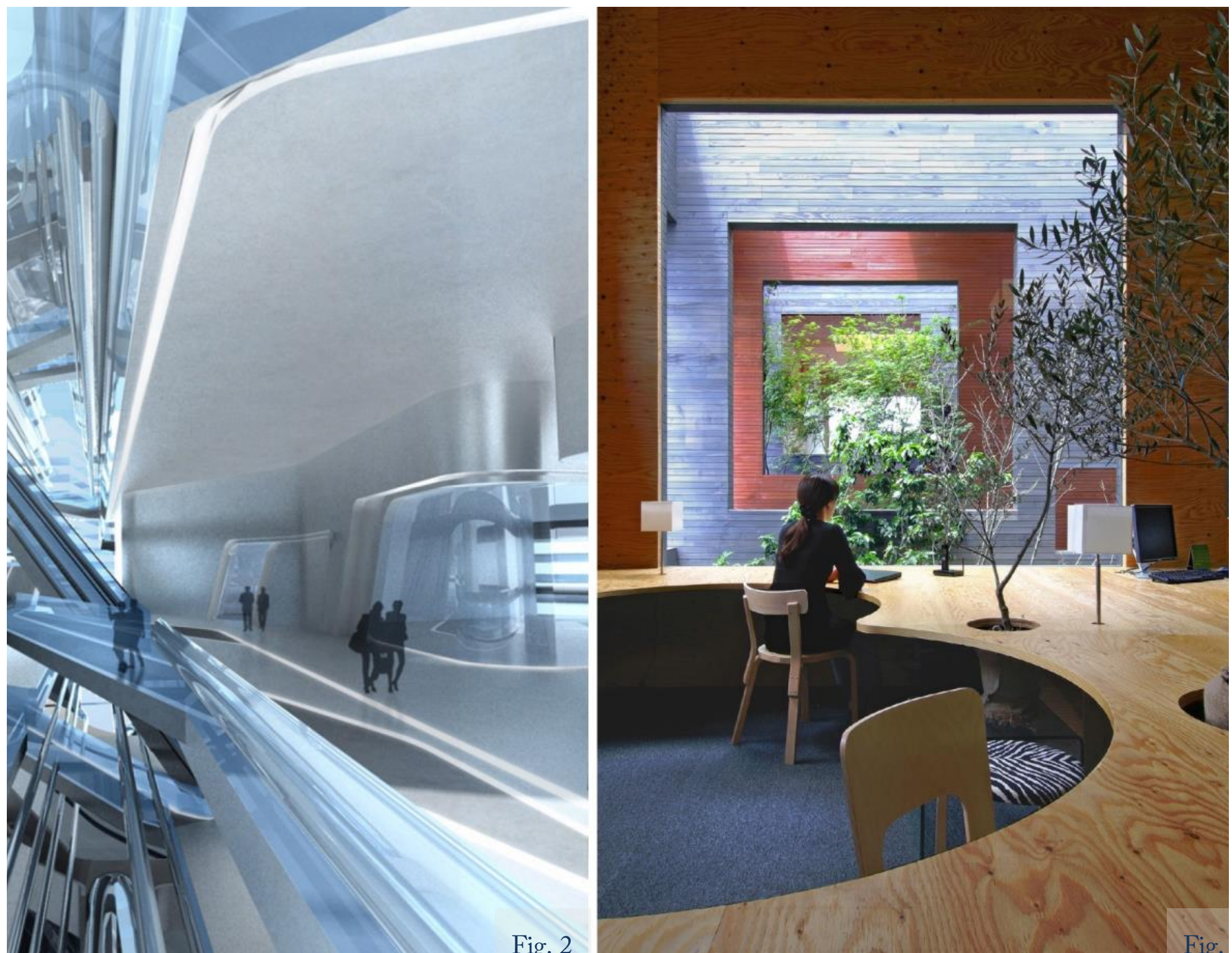
place.

Zaha Hadid's design for the Faculty of Design at the Hong Kong Polytechnic University is illustrated (figure 2). It was completed in 2013 to house the School of Design. The courses offered include Environmental Design, Industrial and Product Design, Visual Communication, Advertising and Digital Design. The executed design offers no opportunity for any 'sense of place' to develop or any relationship with the human being moving through the space, other than to intimidate or awe. The architecture acts as sculptural object - an artwork - and offers or encourages little interaction with its users. Although this is an inspiring architectural work, its sculptural, impersonal quality renders its character disenchanting.

In contrast, the environment of the Mori x Hako Workplace is demonstrated (figure 3). This environment was designed by UID Architects in 2009 in Hiroshima, Japan. This multitenant building has a unique approach. The tenants were involved in the decision-making process, resulting in a successful installation which accommodated their unique spatial requirements. The site is only ten meters wide at its connection to the street, while being fifty meters deep. Typically such a site tends to lead to a situation where the tenant space at the public interface has more favourable conditions compared to those located further back. This design challenged the norm by layering the building, allowing the inner spaces to have additional advantages that equal or surpass the condition of the front space. The 'forest' that was created between the tenant areas produces a physical and psychological separation, aiding in creating various levels of privacy while offering an invigorating, visual incentive.

\section{Towards an understanding of "character"}

The way spaces and places are inhabited varies considerably. The theory of defensible space (Newman, 1996) denotes this difference well as it considers the change in the behaviour of users before and after ownership is taken of a space, which effectively translates an environment into a place. The theory indicates the value of a place as an enchanted environment, since unwanted activities such as vandalism, crime and misconduct are warded off by the elimination of anonymous space. However, it is important to note that postoccupancy studies indicate that an environment designed as a place (intimate and appropriate for a specific set of people), can be experienced as a space (distant and inept) for another set for whose needs the environment was not designed (Strelitz's, 2008). These findings highlight the necessity of intense research and user observation prior to the process of conceptual design. This paper asserts that a design solution can only be successful when all factors influencing the possible use of an environment are considered. The relevance of the social, contextual and corporal context in design is consequently iterated.

Hamdi (2010) explores an anonymous community's vulnerability in his book, 'The placemaker's guide to building community,' to illustrate the troublesome outcome when a project is designed which ill-suits the users' needs. The social housing project was developed according to a standard, modernist (European) solution without researching the local community, resources and culture. A textbook solution was applied to the project whilst completely disregarding the mannerisms and customs of the intended users (Hamdi, 2010: 26). Upon inspection a number of ill-advised decisions in the design proved remarkably problematic: the sit-down watercloset had been broken as the inhabitants are accustomed to 
squat and had climbed on top. The seat was cracked and the pan dislocated. The shower remained unused since the bucket and bowl tradition was favoured, resulting in the hallway regularly flooding. The gas cooker had not been used since residents could not afford the gas; this resulted in a number of families building a makeshift kitchen close to the communal area on the ground floor to cook on open fires (Hamdi, 2010: 25).

In juxtaposition, the Quinta Monroy community housing project in Iquique, Chile, is deemed a very good example of where the architect allowed users the opportunity to take ownership of their environment (figures $4-7$ ). Since the budget for the project was extremely low, the architects rethought the brief and came up with a solution in which the structural elements, that the residents would be unable to do themselves, were all that was provided (Jalocha, 2008). The floor slabs, structural walls and services were thus built, but inhabitants could modify their homes by extending, adapting and finishing at their own discretion. This

Figures 4-7. Photographs before and after residents moved into the Quinta Monroy social housing complex (Kim, 2009). From: http://goo.gl/nO1v8w.
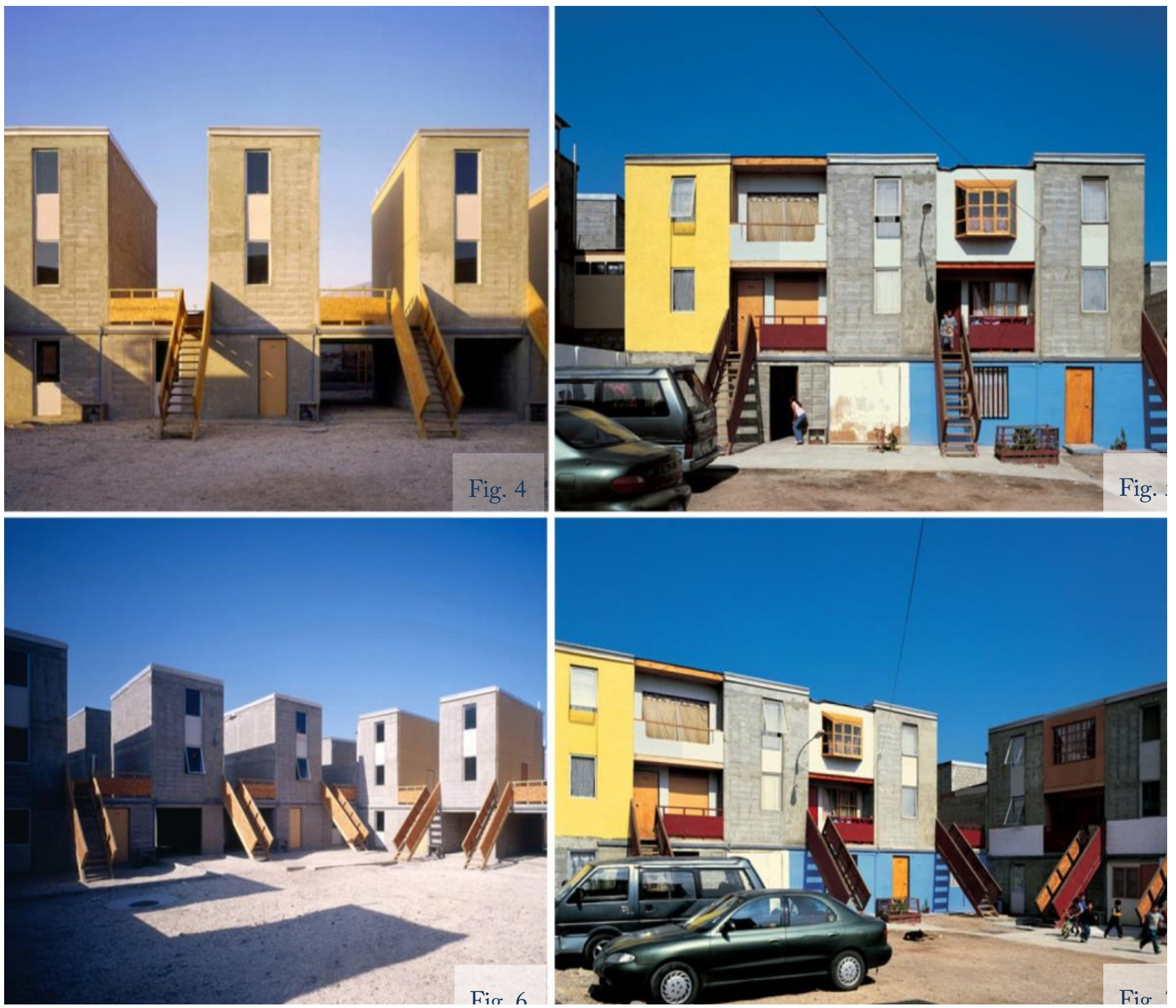
approach showcases every family's home as their own; celebrating each unit as unique.

\section{The enigma}

Architecture can only be deemed successful when it fulfils its purpose of providing apt spaces for its users in a context-conscious manner. This context refers not only to locality and geographical parameters, but also to its relationship with materials, textures, its users, cultural references, spatial requirements and the ability to support the liminality during the development of its users' sense of ownership.

The experiences one has of one's surroundings illustrate that architecture in many instances, has become the fabric of the individual or communities' dream, the escape or the ideal of everyday life and circumstances (De Botton, 2006). In-depth analysis, observation and research are therefore extremely important to enable dwelling and not only building (refer to figure 8), as defined by Heidegger (Heidegger 1971).

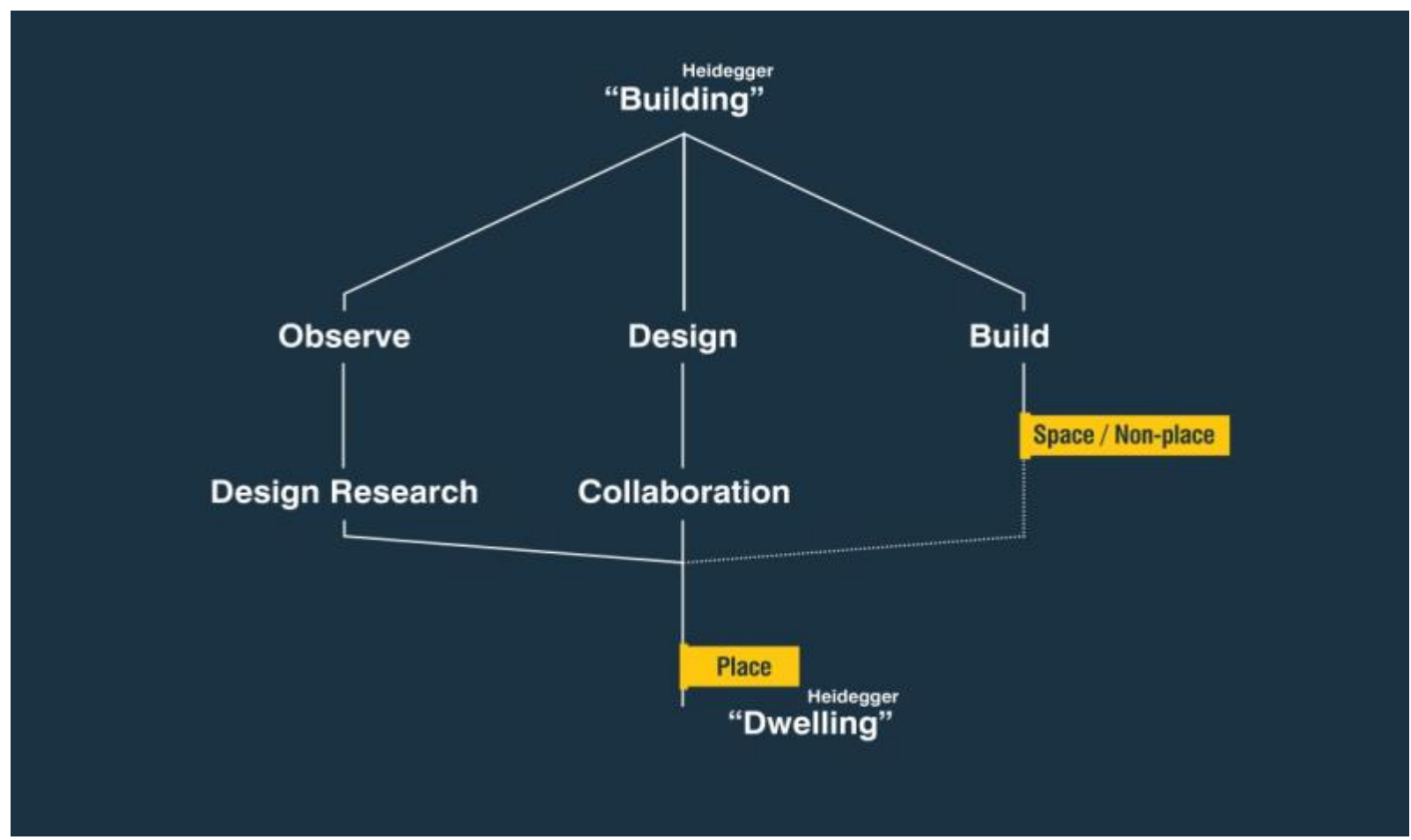

Figure 8. Diagrammatic exploration of Building as opposed to Dwelling (Author, 2014).

This paper states that there is no better way to inform a design process than by observation. Observation is how we learn from history and how we evolve towards tailor-made solutions. Therefore, the design process can be understood as an ecosystem. Only when all components are in equilibrium can the designer start exploring between the tangible and intangible qualities of architecture. The process then concludes in the physical construction phase where the action of building takes place. Heidegger's understanding of building incorporates all three these aspects into one, which then leads to one's ability to dwell within the built structure. 
Therefore, for any designed space or product to be deemed successful, the mediation between what the architect creates and what the user requires need to be completely aligned (Hamdi, 2004: 95).

\section{The singular whole of lived space}

Buildings... are one of the keys to our cultural awareness and practices. Done right, spaces can expand our ability to think and process. Designed poorly, buildings and spaces take from our heart; they literally bleed our energy (Kemp E Baker, 2006: x).

Now that the qualities of space and character have been explored independently, the qualities of the singular whole can be investigated. This paper acknowledges the importance of thoroughly observing and researching the contextual fabric before the act of building. An understanding into the liminal space of a design, where one allows for the community or individuals to take ownership, must be stressed. This sense of ownership (De Botton, 2006:166) is essential for users to experience an environment as a place and not a space. A place is, by extension of the above investigation, any environment that is experienced as enchanted, while a space is experienced as disenchanting.

\section{The Design Process}

We need to recognize the interdependent relationship that exists between the user, the building and the world surrounding it (figure 9). There is abundant potential in multidisciplinary interaction and collaboration within the architect's design process and this aspect needs to be stressed in order to ensure the creation of enchanted places within the built fabric. Heidegger's statement (1971: 160) that 'only if we are capable of dwelling, only then can we build', rings true when we realise that only by understanding how people dwell, can successful architecture be created.

This paper proposes that the relationship between the user, the architectural structures and the contextual fabric should be considered as an interdependent ecosystem. The moment the system falls out of equilibrium, design will result in a composition of spaces, rather than places. It is therefore clear that only when there is harmony between these three components, can successful architecture be created which enable the opportunity for dwelling (Heidegger, 1971). 


\section{Choreographing Experience}

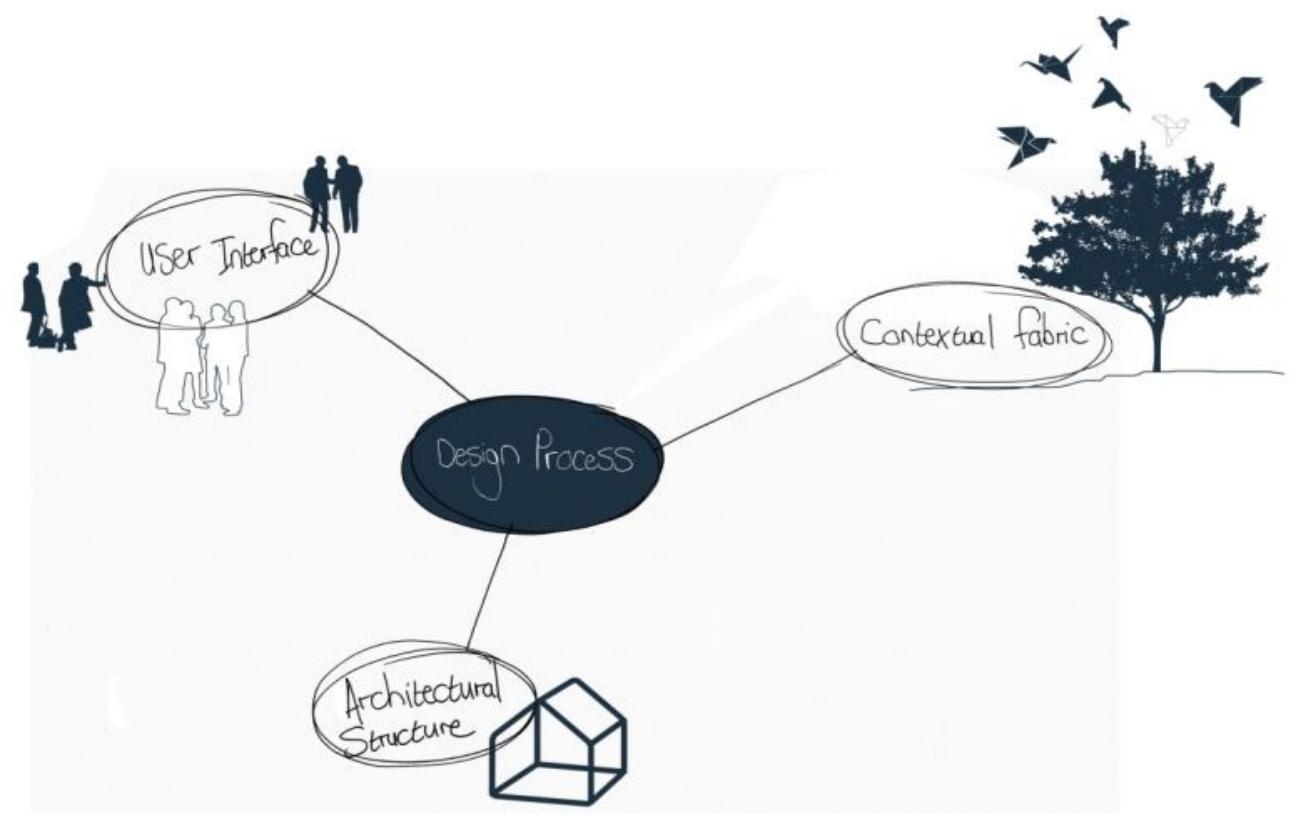

Figure 9. Interdependent ecosystem influencing the design process. (Author, 2015).

The interactions between the user and the environment are found to have a poetic quality when the atmosphere created supports its use. Peter Zumthor developed a vocabulary in his book, Thinking Architecture, where he focuses on the intangible qualities which translates a space into a place. These intangible qualities are just as important as the form-giving tangible qualities. The theory is called "The Magic of the Real" and consist of nine factors which refer directly to a specific 'sense of place', which in turn speaks of the spatial character as first introduced into architectural theory by Norberg-Schultz. The nine factors are explored as follows:

- The body of Architecture which is elaborated on as the frame or body of a space. This factor refers to the skin of space and adds to the sensual experience of the enveloped place;

- Material Compatibility which greatly influences the sense of place. Materials react differently in different combinations, at different times of the day and when used in different amounts. The arrangement of materials greatly exposes the character of a place to our senses;

- The Sound of a Space is explained as a peculiar influence on character. Zumthor stresses that interiors are in essence large instruments as they resonate, collect or absorb sound made within and without. The shape and materials of surfaces all contribute to the sound of a place - it can make you feel at home or it can make you feel abandoned and lonely;

- The Temperature of a Space is understood as both a physical and psychological factor. Steel is cold to the touch, while timber is warm. Each material has an influence on what is seen, felt and touched; 
- Surrounding Objects discusses the things that surround us. The objects within spaces and the way in which they can come together to form a welcoming whole. The details of the things surrounding us greatly influence our senses and how we experience a place;

- Between Composure and Seduction is discussed as the sixth element and elaborates on how people's movement should influence architecture. People move in and through buildings and one's experience is altered in various sequences. Buildings should allow for these movements to be stimulating and relaxing. Movement through a building should appeal to the user and support the uses of the building;

- Tension between Interior and Exterior relates to the threshold of the environments which have the most direct impact on a sense of place. There's a concentration in feeling when one is suddenly being enclosed. The façade acts as a subjective element framing views both to the outside and inside. The way people use the building, the way these views are altered or utilised at different times of the day or year, all influence the atmosphere;

- Levels of Intimacy not only refers to the scale of a space, but also the proximity, distance, detail and mass. It signifies the way space relates to our bodies and how human scale alters the way we experience a space. It is this relationship that ultimately translates a space into a place;

- The Light on Things denotes the way light falls into and within a space. This factor greatly influences an environment's atmosphere. The way materials and surfaces interplay with light by reflecting and absorbing various quantities of light, greatly affects our experience of an environment (Zumthor 2006: 21-57).

These aspects demonstrate the contribution that atmosphere afford to achieve a world with a 'sense of place'. Zumthor's vocabulary will now be investigated in a number of case studies. Each is explored and exploited from within the hermeneutic phenomenological realm of a multi-dimensional context-conscious approach.

\section{Villa Savoye by Le Corbusier}

The Villa Savoye on the outskirts of Paris, France, is one of Le Corbusier's most famous works (figures 10 - 13). The villa was designed as an exploration of Le Corbusier's Five Points for modern architecture and is regarded architecturally as one of the most important buildings of the twentieth century. It is interesting to note, however, that Villa Savoye is also an example of architecture where no liminality between the architect and the user was acknowledged. True to the modern movement's philosophy that the architect was responsible for the complete building and all of its pertaining elements (Berman, 1988: 290-310), the villa was designed as a machine for living.

This is a key example where the relationship and end-result between architect and user is out of balance. To ensure the creation of enchanted environments, this relationship should be in equilibrium; with the one unable to be content if the other is not. An example of this phenomenon is stipulated when Le Corbusier is mentioned in De Botton (2006: 58-59) to have reacted with alarm when Madame Savoye wanted to fit additional furniture in the living room of the Villa. Le Corbusier is said to have merely recommended his clients to keep their belongings to a minimum; stating that furniture was a deplorable notion and that it was to be 
replaced by equipment. Although the villa is rendered as a significant architectural structure, it is evident that the Savoye family experienced it as a space and not a place for living.

Other aspects of the building rendering it unfavourable for living was the leaking roof, the lack of thermal insulation, especially the discomfort of the winter months, and finally, the skylights that were so noisy that the sound prevented the family from sleeping at night.

Figure 10. Living room 2011. Photograph by author. [Transcript]. 4 April 2011. Paris.

Figure 11. Facade 2011. Photograph by author. [Transcript]. 4 April 2011. Paris.

Figure 12. Seamless threshold between interior and exterior. Photograph by author. [Transcript]. 4 April 2011. Paris.

Figure 13. Patio to living room. Photograph by author. [Transcript]. 4 April 2011. Paris.

Therefore, although the Villa is one of the most influential architectural buildings of the last century, it is rendered as a disenchanted environment from the vantage point of the user's experience. The villa was saved from demolition when it was declared a historic monument in 1965. 


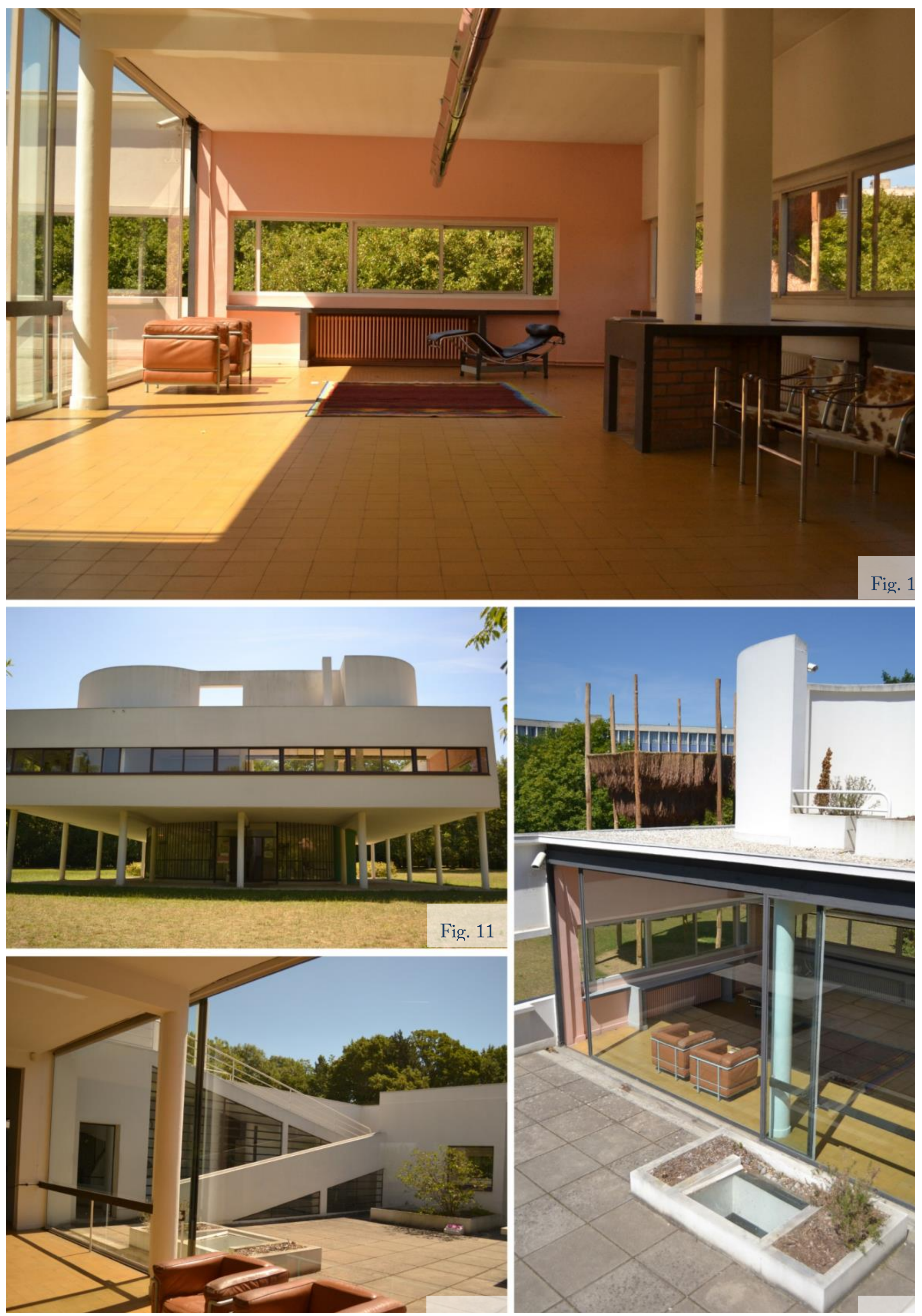




\section{Therme Vals by Peter Zumthor}

Peter Zumthor's Therme Vals is a hotel and spa in Switzerland. This bathing complex, completed in 1996, was constructed over the thermal springs of the Graubunden Canton. The building respects the previously existing hotel complex, while acknowledging the unique emotional and physical conditions required of contemporary bathing rituals. This phenomenon is referred to as the 'art of bathing' and influenced the ebb and flow of the building's spatial character (figures $14-18$ ), not only internally and externally, but also its identity within the spatial matrix of the village. The community of Vals were consulted during the design process and included in major decisions during the design's development (Hauser \& Zumthor, 2007).

The result is an architecture that not only speaks to the social and geographical fabric in which it is placed, but also to its users and the experience they desire when within its boundary walls. The informed design approach is reflected in the materiality (locally quarried Valser Quarzite slabs), intimacy of the various spaces, the sounds and the overall tension between interior and exterior. Visitors are encouraged to meander through the various areas, creating their own journey towards tranquillity and restoration. The various thresholds between areas are composed with light and darkness, sounds and varying levels of intimacy. The Therme Vals is considered a particularly well designed model for enchanted space. The arrangement and configuration of the different environments, as well as their varying characters, all contribute to the bathing complex being experienced as enchanting.

Figure 14. Exterior view (Unknown, 1996). From: ttp://goo.g1/FUVumygoo.g1/n9uhLm.

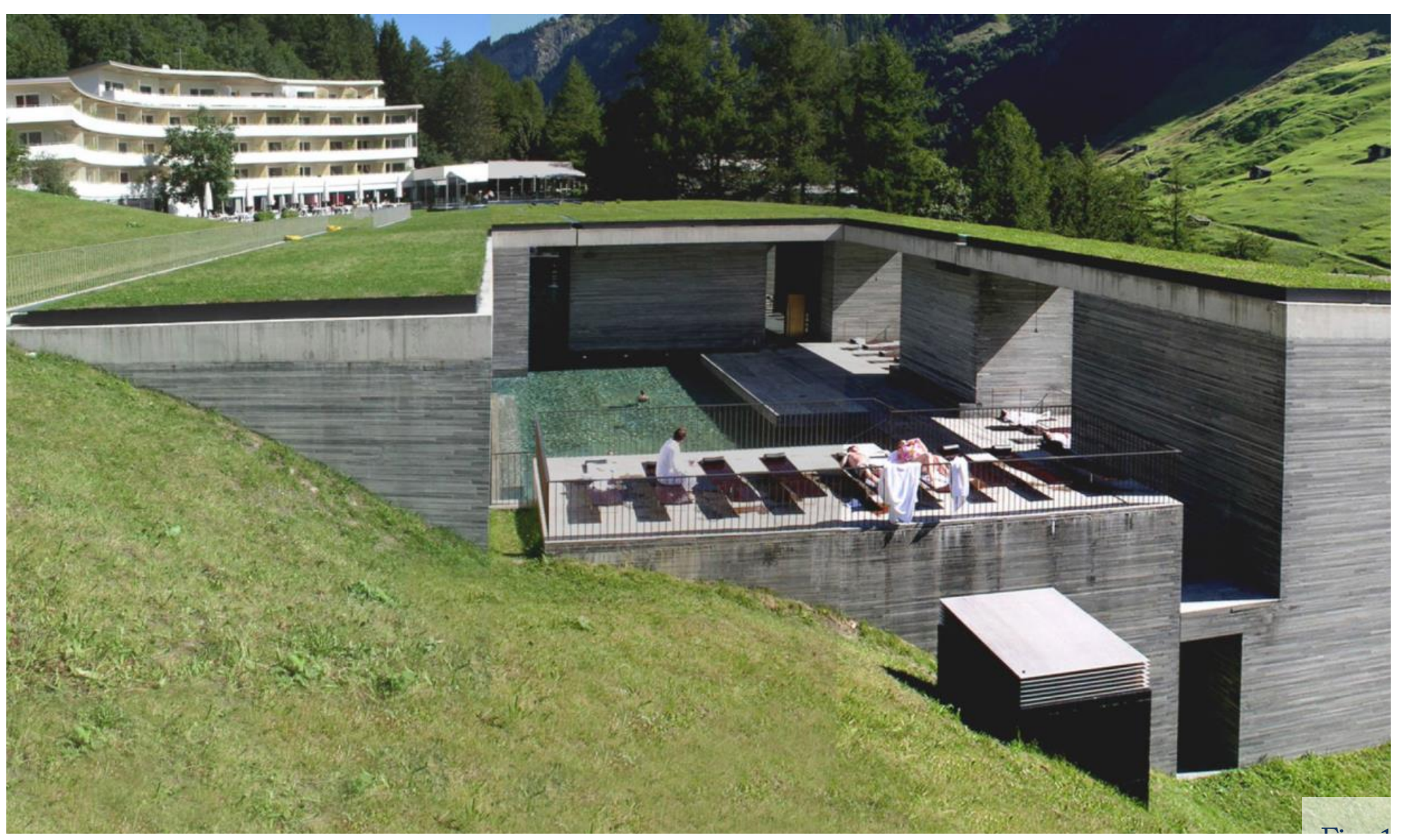




\section{Kiasma museum of Contemporary Art by Steven Holl}

The Kiasma Museum of Contemporary Art by Steven Holl in Helsinki, Finland, is another example where the intangible and tangible qualities of the architectural environment fuse into a singular opus of enchanted space. Holl utilised light as the most significant element of the architectural palette (figures 19 - 22). The amalgamation and arrangement of the blend between natural and artificial light entering the spaces were used as architectural medium for

Figure 15. Interior detail (Unknown, 1996). From: https://goo.g1/YMmUaF.

Figure 16. Tension between interior and exterior (Unknown, 1996). From: http://goo.g1/5y0Nts.

Figure 17. Interior character of bathing area (Unknown, 1996). From: http://goo.gl/p7xAnI.

Figure 18. Exterior character of bathing area (Unknown, 1996). From: http://ideasgn.com/wpcontent/uploads/2013/04/Therme-Vals-Switzerland-by-Peter-Zumthor-003.jpg.
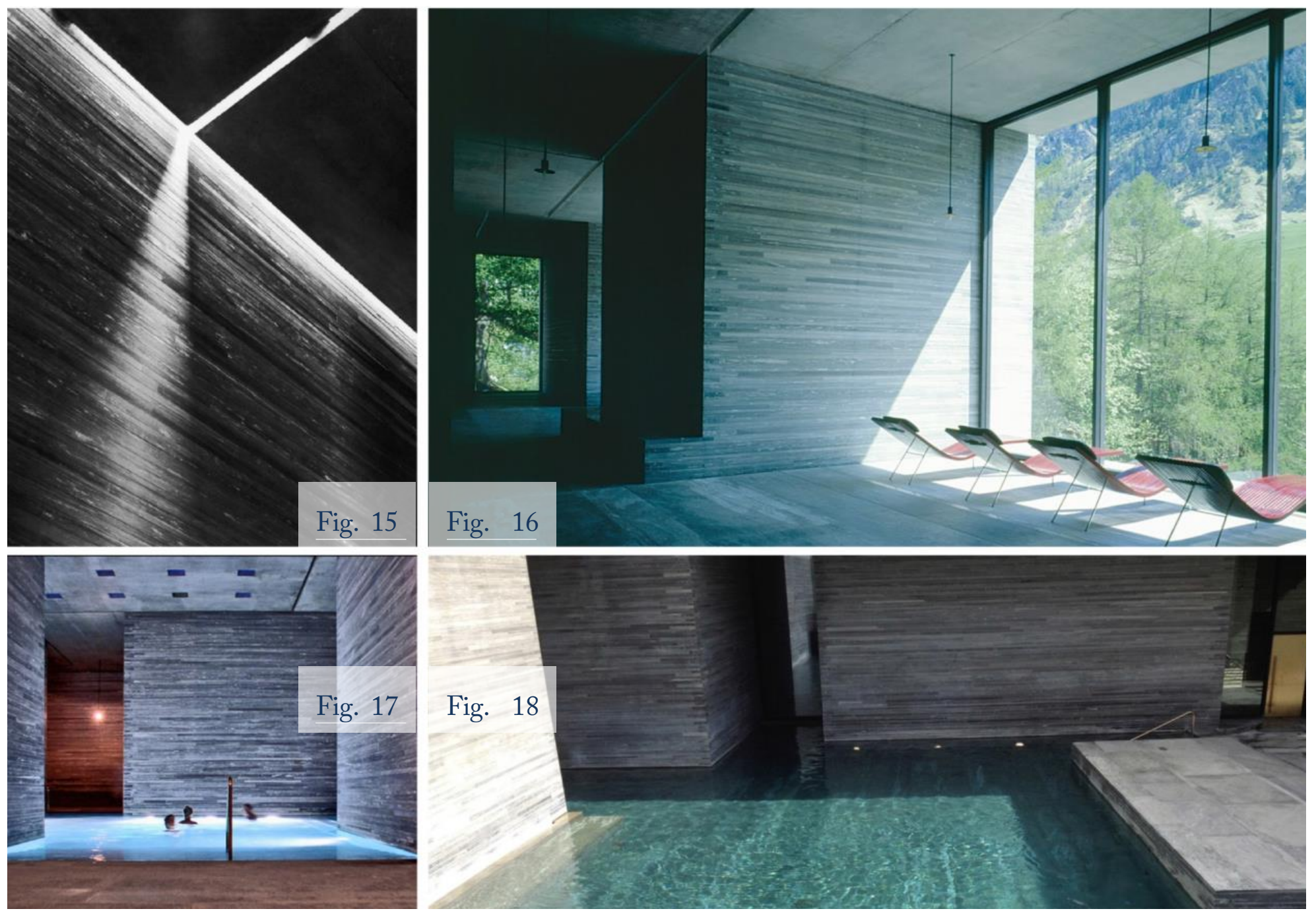
the composition of various types of spatial characters within the museum.

The spatial configuration, which can be related to Zumthor's concepts of intimacy, movement, composure and seduction, are all arranged into a collective, harmonious whole. The journey through the museum was designed to be interactive and without hierarchy. The thresholds between the various exhibition rooms offer visitors a moment of repose, with a variation in scale and proportion. The museum is experienced as a matrix of places, as the composition and transitions allow for various degrees of intimacy and enchantment. Finally, it is rendered as a successful endeavour for the exhibition of Modern Art as the pieces appear uniquely posed within the fascinating variety of spatial and lighting compositions.

Figure 19. Atrium 2011. Photograph by author. [Transcript]. 28 June 2011. Helsinki.

Figure 20. Modern Art exhibited in natural light 2011. Photograph by author. [Transcript]. 28 June 2011. Helsinki.

Figure 21. Atrium ramp 2011. Photograph by author. [Transcript]. 28 June. Helsinki.

Figure 22. Exhibition area 2011. Photograph by author. [Transcript]. 28 June 2011. Helsinki. 

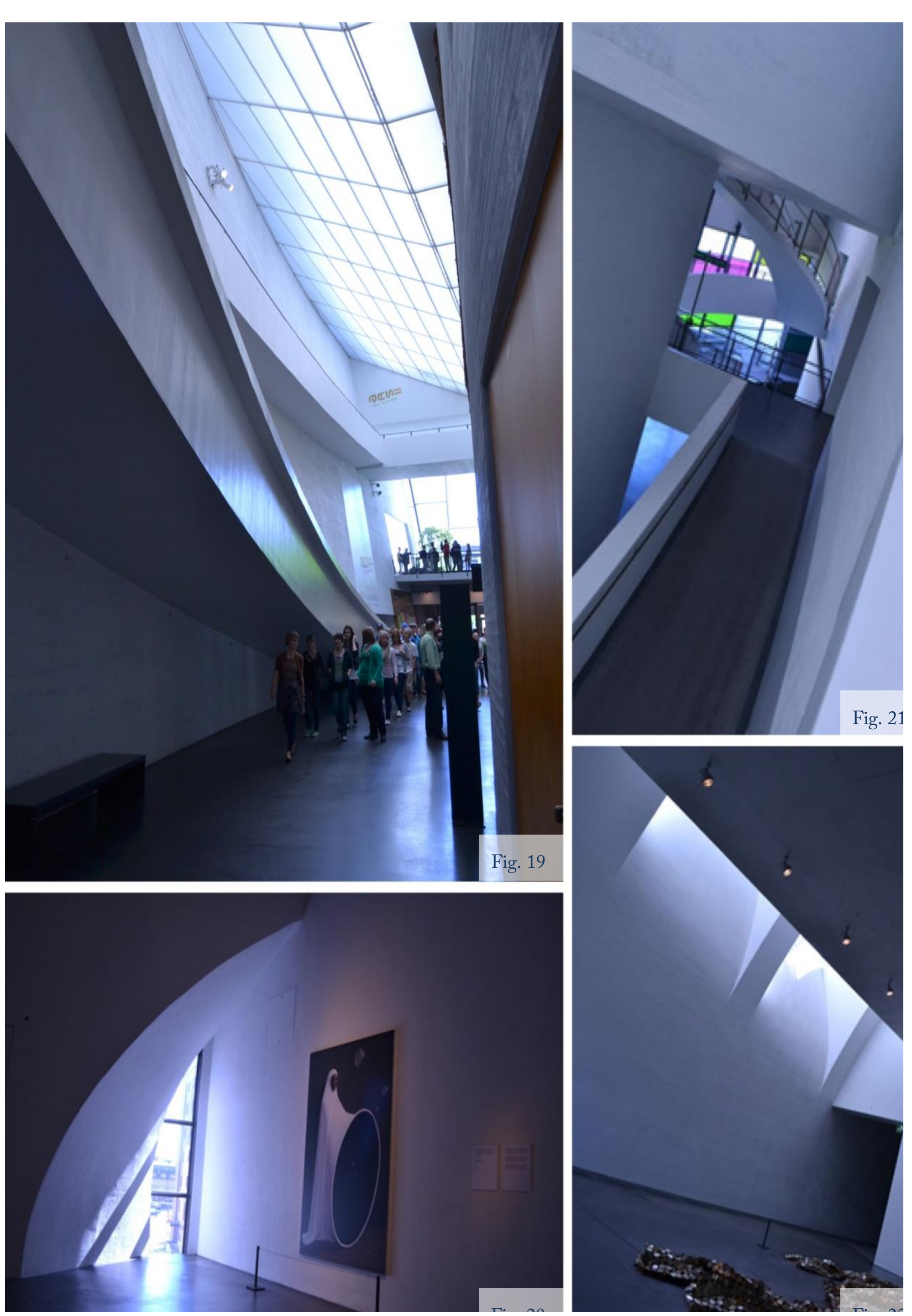


\section{Conclusion}

The pursuance of building an enchanted world was captured in the statement by Heidegger (1971:160) as 'only if we are capable of dwelling, only then can we build'. The interdependence that exists between the user, the building and the world surrounding it was delineated and explored. Only when places, and not spaces are designed, can we develop a built fabric which can be deemed enchanting. The spatial quality of an environment and its two defining parameters, namely space and character, was explored individually, where after the interdependence between these qualities was investigated.

The theoretical argument was developed with the importance of context at its core, whereafter hermeneutic phenomenology's relevance and influence on contemporary architectural thinking was indicated. The importance of research and observation prior to design was delineated, ensuring an informed and apt solution. The distinctions between an enchanted and disenchanted world was illustrated through an analyses of the spatial character's tangible and intangible qualities. Finally, the juxtaposition between enchanted and disenchanted environments was illustrated in the sense of intimacy or sense of distance created for the user.

\section{References}

Augé, M. 1995. Non-Places: Introduction to an Anthropology of Supermodernity. Trans. Howe, J. Verso: London.

Bachelard, G., 1969. The Poetics of Space. Beacon Press: Boston.

Berman, M., 1988. All That Is Solid Melts Into Air: The Experience of Modernity. Penguin Books: New York.

Bermudez, J. 2015. Transcending Architecture. The Catholic University of America Press: Washington, D.C.

De Klerk, S, 2013. An exploration of office design : Understanding the character of our workplaces. MInt(Prof) dissertation, University of Pretoria, Pretoria. [Online.] Available from: http://hdl.handle.net/2263/32806 [Accessed 1 August 2014].

De Botton, A. d., 2006. The Architecture of Happiness. Vintage Books: New York.

Hamdi, H. 2004. Small Change: About the Art of Practice and the Limits of Planning in Cities. Earthscan: London.

Hamdi, N., 2010. The Placemaker's Guide To Building Community. Earthscan: London.

Hauser, S., \& Zumthor, P., 2007. Therme Vals. 3 (expanded) ed. Verlag Scheidegger and Spiess: Basel.

Heidegger, M. 1971. Building Dwelling Thinking. Trans. A, Hofstadter. Harper Colophon Books: New York.

Heidegger, M. 2008. Being and Time._Trans. J, Macquarrie and E, Robinson. Harper and Row Publishers: New York.

Holl, S. 1991. Anchoring. Princeton Architectural Press: New York. 
Holl, S., Pallasmaa, J. \& Perez-Gomez, A., 2007. Questions of Perception: Phenomenology of Architecture. 2 ed. William Stout Publishers: San Francisco.

Husserl, E. 2012. Ideas: General Introduction to Pure Phenomenology. Trans. W.R.B. Gibson. Routledge: New York.

Jalocha, 2008. Quinta Monroy. [Online.] Available from: <http://www.archdaily. com/?p=10775> [Accessed 14 June 2013].

Kemp, J.M., \& Baker, K. 2007. Building Community in Buildings: The Design and Culture of Dynamic Workplaces.Praeger: London.

Merleau-Ponty, M., 1996, Phenomenology of Perception. Trans. C, Smith. Routledge: New York.

Newman, O. 1996. Creating Defensible Space. Diane Publishing Company: Collingdale.

Norberg-Schultz, C. 1996.The Phenomenon of Place. In Nesbitt, K. ed. Theorizing a new agenda for architecture. Princeton Architectural Press: New York, 412-428.

Norberg-Schultz, C. 1984.Genius Loci - Towards a Phenomenology of Architecture. New York: Rizzoli.

Pallasmaa, C. 1996. The Geometry of Feeling. In Nesbitt, K. ed. Theorizing a new agenda for architecture. Princeton Architectural Press: New York, 447-453.

Pallasmaa, J. 2015. Light, silence, and spirituality in architecture and art. In Bermudez, J. ed. Transcending Architecture. The Catholic University of America Press: Washington, D.C., 29-32.

Sharr, A, 2010. Heidegger for Architects. Routledge: New York.

Strelitz, Z. 2008. Buildings that feel good. Riba Publishing: London.

Zumthor, P. 2006. Atmospheres: Architectural Environments and Surrounding Objects. Birkhäuser Architecture: Basel.

Zumthor, P. 2010 .Thinking Architecture. 3 (expanded) ed. Birkhäuser Architecture: Basel. 